\title{
VISUALIZATION INVESTIGATION ON THE MARINE DATA WITH MULTIVARIATE STATISTICAL ANALYSIS METHODS
}

\author{
Li Yajie, Ph.D., \\ Lv Zhengdong, B.S., \\ Wang Maonan, B.S., \\ Beijing University of Posts and Telecommunications, Beijing, China
}

\begin{abstract}
Marine information is an important way for us to know and study more about the ocean. Marine data makes the basic of marine information. Because of the huge quantity and diversity of marine data, and at the same time marine data is polyatomic variable, we start with statistical analysis methods to search for the regularity of the marine data. On one hand, we get the aggregate variation functions of the marine data by factor analyzing in aspect of the spatiality. Then we visually describe the marine status of the studied sea area with pre variogram function and post variogram function. On the other hand, we used cluster analysis method to get the verifying rule in time and make visible graphs of the marine data. In this way, we can also supply with the suggestions in classifying the sea seawater quality. The data processing result shows that the suggested methods in this article are both operable and effective. At the same time some reasonable suggestions are given in the article.
\end{abstract}

Keywords: marine data; factor analysis; cluster analysis, discriminate analysis; visualization

\section{INTRODUCTION}

The sea is closely related to a country's environmental protection, the resources developing and its national safety as well. And marine information is one of the important methods to know and study the sea [1]. Marine data is the basic of marine information. We can give important proves for studies in marine environmental monitoring, marine resources detecting and marine disasters forecasting [2]. Human's vision sense did great contribution to scientific studies. The conception of visualization was started to be used in the 80 s in the 20th century. The massive of data could be converted into graphs in a visualization process. The graphs inspire our image thinking abilities which greatly improves data processing. Human's main visualization skills contain scalar field visualization, vector field visualization [3] and feature-based visualization $[4,5]$. There are many marine data visualization studies in the world. For example, United States Naval Research Laboratory (NRL) made an data visualization research on the mixing process of the ocean in 1989. In the European eScience plan sponsored by the British National Institute for Environmental eScience (NIEeS) they started the research plan GODIVA [6] (Grid for Ocean Diagnostics, Interactive Visualization and Analysis). In this plan, they used the interactive visualization technology and network technology to process marine data. Poseidon [7], the oceanography study project was led by MIT. They used distributed computing as their basic method to integrate the marine data and made the model as well as functional modules, visualization and parameter calculation, etc. Visualization of marine data makes the ever changing massive marine data effectively used which helped to process and explain the marine data with high efficiency. 


\section{MATERIAL AND METHODS}

\section{CHARACTERISTICS OF THE MARINE DATA}

Containing massive amount of information is a characteristic of marine data. The main method to collect marine data is to use remote sensing satellites and buoys. The seasats can help us to collect marine data by using the seasat sensors. Till 2012, more than 40 seasats have been sent to the out space by America, Australia and some other costal countries in the world. There are sea-viewing satellites for observing the seawater colours like Terra, Aqua and AMSE, etc. And sea-viewing satellites for observing the sea terrains like Topex, Poseidon, Jason-1/2, and CESat, etc. And also satellites for observing ocean dynamic like ERS-1/2, Envisat, HY-2, etc. The amount of the original marine data collected by the seasats is enormous. About 8500 agro buoys have been set on the sea by over 30 costal countries like US and Australia [8] which made a big sea monitoring network in the last 20 years. These buoys can collect the temperature information of the upper layer of the sea as well as some other data. Out from 1042 observing platforms of the National Data Buoy Center (NDBC) of America, 758 of them can supply realtime data [9].

Diversification is another character of the marine data. There are some main types of marine data like marine data collected by remote sensing seasats, hydrologic data, meteorological data, chemical data and biological data. And elements and forms contained by each type of marine data vary one to antoher. Marine chemical data contains dissolved oxygen, $\mathrm{PH}$ value, total alkalinity, active phosphorus, active silicate, acid salt, nitrate, nitrite, sulfide, organic pollution, and heavy metal and nutrient elements in forms like excel, mdb, csv, xml, etc. Another example proving that marine data varies in forms and types is that hydrologic data shows water temperature, height of tide, time of tide, salinity, wave number, wave height, water depth and transparency of the water, etc [10]. And if the data is collected by different monitoring instruments the data forms is different from each other. For example, we can see there are three types of form the marine data collected by remote sensing seasats: NUMBER (8) (20170408), String (10) (2016/04/08), NUMBER (4) (2) (2). Marine data has varies characteristics and types in different forms. This characteristics and types of marine data and data forms rely on each other and influences one another [11].

\section{METHODS}

Spatial is another attribute of the marine data and the data from different space have connections to each other. Marine data also has time attribute and data collected at different time are multivariate variable[12]. We want to do the study on the visualization work of the marine data in both the special aspect and the time aspect. At first, we use the simulated marine data to explain our working method and then do actual data analysis with real data. Let us say that the data in this simulate marine data are collected form $\mathrm{N}$ stations and there are $\mathrm{P}$ attributes $\mathrm{C}_{1}, \mathrm{C}_{2}, \ldots, \mathrm{C}_{\mathrm{p}}$, in data from each station described in the following chart(here $\mathrm{N}$ and $\mathrm{P}$ stands number). See chart Tab.1:

Tab. 1. Marine Data Simulation

\begin{tabular}{|c|c|c|c|c|}
\hline Station & $\mathrm{C}_{1}$ & $\mathrm{C}_{2}$ & $\ldots$ & $\mathrm{C}_{\mathrm{p}}$ \\
\hline $\mathrm{A}_{1}$ & $\mathrm{C}_{11}$ & $\mathrm{C}_{12}$ & $\ldots$ & $\mathrm{C}_{1 \mathrm{p}}$ \\
\hline $\mathrm{A}_{2}$ & $\mathrm{C}_{21}$ & $\mathrm{C}_{22}$ & $\ldots$ & $\mathrm{C}_{2 \mathrm{p}}$ \\
\hline$\vdots$ & $\vdots$ & $\vdots$ & $\vdots$ & $\vdots$ \\
\hline $\mathrm{A}_{\mathrm{n}}$ & $\mathrm{C}_{\mathrm{n} 1}$ & $\mathrm{C}_{\mathrm{n} 2}$ & $\ldots$ & $\mathrm{C}_{\mathrm{np}}$ \\
\hline
\end{tabular}

\section{SPECIAL ATTRIBUTE OF MARINE DATA}

In order to inspect and study the special attribute of the marine data, let us say that the simulated marine data in table 1 was collected at certain time. This time could be a certain year, a season, a month, one day or an accurate time. We can set the time according to our studying targets. In this article we assume that we collected marine data in a certain year from $\mathrm{N}$ inspection stations and the data has $\mathrm{P}$ types of characteristics (here $\mathrm{N}$ and $\mathrm{P}$ stands for numbers).

If the sea is calm, then the data collected from the close stations would be relatively stable and tend to be similar. Then what are close stations? There are many characteristics, how can we define stable and similar? First of all, we need to find the close stations. We start from a station marked as $A_{(1)}$. Then we go to the closest stations marked as $A_{(i)}$. $A_{(2)}$ is the closest station to $A_{(1)}$. We mark closest station from $A_{i}$ to $G_{(1)}$ (A and $G$ are station types and $G_{(1)}$ is formed by $A_{(1)}$ and $\left.A_{(2)}\right)$ as $A_{(3)}$. Then we get the close stations $A_{(1)}, A_{(2)}, \ldots, A_{(n)}$ to $A_{(1)}$. The distance to $A_{(1)}$ increases from $A_{(1)}$ to $A_{(n)}$.

In the discussion above, we talked about the distance between stations and between stations groups of different types. We get samples $\mathrm{x}_{\mathrm{i}}$ and $\mathrm{x}_{\mathrm{i}}$. We mark the distance between the two samples $i$ and $j$ as $d_{i j}$. We have some types we station distance like Euclidean distance:

$$
d_{i j}=\left(\sum_{k=1}^{p}\left|x_{i k}-x_{j k}\right|^{2}\right)^{1 / 2}
$$

There are eight types of separation distances we often use in our esearches. We use $G_{p}$ and $G_{q}$ to mark two distance types. And the number of samples in each types marked as $n_{p}$ and $n_{q} . D_{p q}$ describes the distance between type $G_{p}$ and type $\mathrm{G}_{\mathrm{q}}$. If we apply the method to describe the average distances between different types. The average distance between both types is the distance square in between:

$$
D_{p q}^{2}=\frac{1}{n_{p} n_{q}} \sum_{x_{i} \in G_{p}} \sum_{x_{j} \in G_{q}} d_{i j}^{2}
$$


To make it easier to operate, we normally choose Euclidean distance as the distance between two stations and use the group average methods to describe the separation distance.

Now let's come to the second question: how to define and measure stable? On the first step, since there are marine data with $\mathrm{P}$ attributes (here $\mathrm{P}$ stands for number) in each station, there are large amount of attribute values, we descend he dimension of the variables with factor analysis method and measure the data stability of each station with general factor F. The work procedure is listed below:

Step I: standardize the original variables. We usually need to standardize the dimension of each attribute to make the data comparable. We mark the standardized attribute as $\mathrm{C}_{\mathrm{ij}}$. Then we evaluate for $\mathrm{C}_{\mathrm{ij}}$ 's matrix $\mathrm{R}$ and its characteristic root $\mathrm{w}_{\mathrm{i}}$. The biggest characteristic root is marked as $\mathrm{w}_{1}$ and the characteristic value decries from $\mathrm{w}_{1}$.

Step II: evaluate the original common factor $\mathrm{F}$ and the factor load matrix with principal component analysis method.

Step III: Apply the orthogonal rotation method with maximized deviations to rotate the factor. Step IV: In this step we choose and explain the factors. Step V: Use the regression method to evaluate the factor score. See chart Tab .2.

In the real life, if we get the result that if the accumulated variance contribution rate :

$$
\frac{\sum_{i=1}^{k} w_{i}}{\sum_{i=1}^{n} w_{i}} \geq 70 \%
$$

We can say that we have collected the good original data. The value of common factor $F$ is the weighted value of $F_{1}, \ldots, F_{k}$ which means $\mathrm{F}=\mathrm{w}_{1} \mathrm{~F}_{1}+\ldots+\mathrm{w}_{\mathrm{k}} \mathrm{F}_{\mathrm{k}}$. Then the weighted factor score of factor $\mathrm{F}$ we got from station $\mathrm{A}_{(\mathrm{i})}$ is $\mathrm{F}_{(\mathrm{i})}$.

Tab. 2. Simulated Marine Data in a certain year

\begin{tabular}{|c|c|c|c|c|c|}
\hline Station & $\mathrm{C}_{1}$ & $\mathrm{C}_{2}$ & $\ldots$ & $\mathrm{C}_{\mathrm{p}}$ & $\mathbf{F}$ \\
\hline $\mathrm{A}_{(1)}$ & $\mathrm{C}_{11}$ & $\mathrm{C}_{12}$ & $\ldots$ & $\mathrm{C}_{1 \mathrm{p}}$ & $\mathrm{F}_{(1)}$ \\
\hline $\mathrm{A}_{(2)}$ & $\mathrm{C}_{21}$ & $\mathrm{C}_{22}$ & $\ldots$ & $\mathrm{C}_{2 \mathrm{p}}$ & $\mathrm{F}_{(2)}$ \\
\hline$\vdots$ & $\vdots$ & $\vdots$ & $\vdots$ & $\vdots$ & $\vdots$ \\
\hline $\mathrm{A}_{(\mathrm{n})}$ & $\mathrm{C}_{\mathrm{n} 1}$ & $\mathrm{C}_{\mathrm{n} 2}$ & $\ldots$ & $\mathrm{C}_{\mathrm{np}}$ & $\mathrm{F}_{(\mathrm{n})}$ \\
\hline
\end{tabular}

Then we measure the stability with the differential function of spatial value $\mathrm{F}$ (marked as FF). The calculation formula is:

$$
F F_{i}=F_{(i)}-F_{(i-1)}, i=2, \ldots, n
$$

If the sea is calm, then the data collected from the close stations would be relatively stable and tend to be similar. This also means there should be no big difference between the value of $\mathrm{FF}\left(\mathrm{FF}_{\mathrm{i}}\right)$ we got at the beginning and the value of $\mathrm{FF}\left(\mathrm{FF}_{\mathrm{i}+1}\right)$ we got later. To make it visible, we put $\mathrm{FF}_{\mathrm{i}}$ and $\mathrm{FF}_{\mathrm{i}+1}$ into a scatter diagram. The coordinate of the first spot in the diagram is $\left(\mathrm{FF}_{\mathrm{i}}, \mathrm{FF}_{\mathrm{i}+1}\right)$. This idea was inspired by the scatter diagram electrocardiogram RR-Lorenz [13]. When the sample contains large amount of data, the scatter diagram shows like a baseball bat when the sea is calm. In this scatter diagram the line in center of the scatterplots has its gradient close to 1 . We can also apply the regression analysis method to get the equation of the line for prediction purpose.

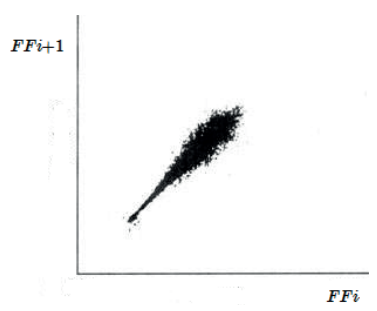

Fig. 1. FF-FF Scatter Diagram

\section{TIME ATTRIBUTE OF MARINE DATA}

We take the marine data collected from a same station for example. Let us use $\mathrm{A}_{(1)}$ for the station. There are $\mathrm{P}$ attributes $\mathrm{C}_{1}, \mathrm{C}_{2}, \ldots, \mathrm{C}_{\mathrm{p}}$ in station $\mathrm{A}_{(1)}$. In the data we use here we add the time that the data was collected as a part of the data. The collecting time could be a certain year, a month, a day or an accurate time. For example we can use days in our study. For example 1/1/2017 stands for mid day time of Jan. $1^{\text {st }} 2017$ as showed in Tab.3.

We can observe if there are clustering phenomena in the data we used in the study to the characteristics of time. We start with hierarchical clustering method to determine how many types we need. Say if we need $k$ types of data, we need to apply K-means clustering method to do fast cluster analyzing to the data. We can classify $\mathrm{G}$ different types data into good, medium and low level according to the sea water quality standards and the central value classification we got from the K- means value clustering analyzing method .

Tab. 3. Simulate Marine Data from a same Station

\begin{tabular}{|c|c|c|c|c|c|}
\hline Collecting Time & $\mathrm{C}_{1}$ & $\mathrm{C}_{2}$ & $\ldots$ & $\mathrm{C}_{\mathrm{p}}$ & $\mathbf{G}$ \\
\hline $1 / 1 / 2010$ & $\mathrm{C}_{11}$ & $\mathrm{C}_{12}$ & $\ldots$ & $\mathrm{C}_{1 \mathrm{p}}$ & $\mathrm{G}_{1}$ \\
\hline $1 / 2 / 2010$ & $\mathrm{C}_{21}$ & $\mathrm{C}_{22}$ & $\ldots$ & $\mathrm{C}_{2 \mathrm{p}}$ & $\mathrm{G}_{1}$ \\
\hline$\vdots$ & $\vdots$ & $\vdots$ & $\vdots$ & $\vdots$ & $\vdots$ \\
\hline $4 / 7 / 2017$ & $\mathrm{C}_{\mathrm{n} 1}$ & $\mathrm{C}_{\mathrm{n} 2}$ & $\ldots$ & $\mathrm{C}_{\mathrm{np}}$ & $\mathrm{G}_{2}$ \\
\hline
\end{tabular}

Then we can make several types of statistical graphics like the Chernoff faces graph $\mathrm{C}_{\mathrm{ij}}$ and the broken line graph of clustering value $\mathrm{G}$, etc. of the collected data.

\section{EMPIRICAL ANALYSIS}

We choose some buoy data we quoted from the American National Data Buoy Centre (NDBC) website as our sample (see Fig. 2). Since the two types of buoys showed in triangle shape and diamond shape in the website stand for different types of data, we choose the data presented by the diamond shaped buoy in our article. We chose three groups of data 
collected with buoys separately from the top, middle and the bottom. When the buoy is selected, it turns red. We can get the data we need when we input the information about time and data type by selecting in the web. Then we can get implications and scopes or each attribute by clicking submit.

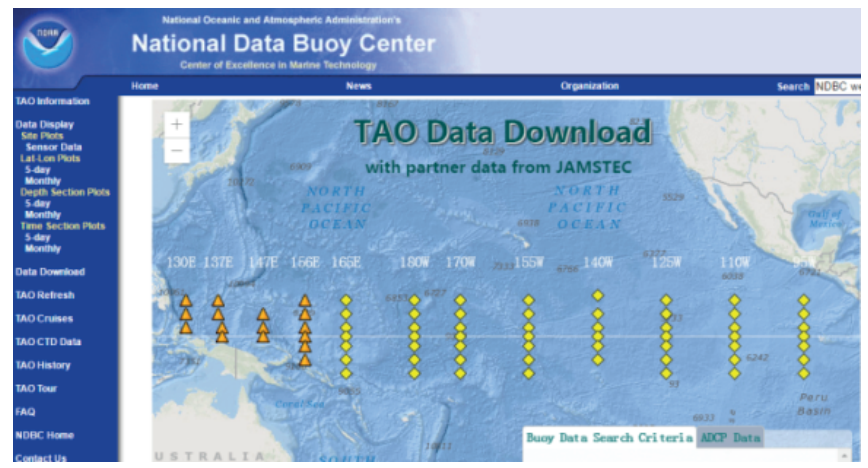

Fig. 2. Marine data form a sea area

Data source: http://tao.ndbc.noaa.gov/tao/data_download/search_map.shtml

When we choose 24 buoys as the sample data resources (considered location factor we chose T8N165E,T0N165E, T8S 165E,T8N180W,T0N180W,T8S180W,T8N170W,T0N170W,T8 S170W,T8N155W,T0N155W,T8S155W,T9N140W ,T0N140W ,T5S140W,T8N125W,T0N125W,T8S125W,T8N110W,T2S110 W,T8S110W,T8N95W,T0N95W,T8S95W).

We noticed that there are two buoys with big difference in attribute from the others so we deleted the related data and the sampled buoys reduced to 22(T0N140W,T0N170W). These buoys are marked as $\mathrm{A}_{(1)}, \mathrm{A}_{(2)} \ldots, \mathrm{A}_{(22)}$.

The observing time is from $1 / 1 / 2012$ to $4 / 7 / 2017$. We got the data showing 9 attributes (Surface - Met, Wind, Relative Humidity, Air temperature, Sea surface Temp, Subsurface temp, Sea water pressure, Salinity, Density). And in this data pack there are at most 46 sub-attributes. The data form got from the website is ASCII (American Standard Code for Information Interchange). In order to do the study in this article, we converted the data form into CSV (compatible of Excel).

Marine data has the characteristic of huge amount and multiformity, it also varies in time and space. Each buoy (station) has the information of time, space, hydrological attribute elements and the monitored marine data. We processed the missing information (with near interpolation method and mean value interpolation method) and sorted the data characteristics collected from different stations. As a result, 23 sub-attributes including time, AIRT, SSD, UWND, VWND, WSPD, WDIR, AIRT, RH, PRES, PRES, SSS, SST and TEMP, etc are analyzed in the process. The total value quantity of this data was over 30 thousand. A part of the values are shown in the chart below:
Tab. 4. Chart for the processed data of marine data from a sea area

\begin{tabular}{|c|c|c|}
\hline & YYYYMIDD & 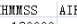 \\
\hline 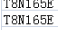 & 2012120102 & 1200000 \\
\hline $1165 \mathrm{E}$ & 20120104 & \\
\hline & 010101 & 120000 \\
\hline & 20120106 & \\
\hline $\begin{array}{l}\mathrm{N} 165 \mathrm{E} \\
\mathrm{N165F}\end{array}$ & 20120107 & 120000 \\
\hline & 2012010108 & \\
\hline 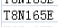 & 20120109 & $\begin{array}{l}1200000 \\
1200000\end{array}$ \\
\hline T8N165E & 20120111 & 120000 \\
\hline 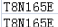 & & \\
\hline $\begin{array}{l}88 N 1658 \\
78 N 1658\end{array}$ & 20120113 & 1200000 \\
\hline $\begin{array}{l}165 \mathrm{E} \\
165 \mathrm{E} \\
\end{array}$ & 20120114 & 120000 \\
\hline $\begin{array}{l}\text { N165e } \\
\text { N165e }\end{array}$ & 20120115 & 1200000 \\
\hline & & \\
\hline$\frac{78 N 165 E}{8026}$ & 20120118 & 120000 \\
\hline T8R165e & 20120119 & 120000 \\
\hline 1658 & 20120120 & 120000 \\
\hline $165 \mathrm{E}$ & 20120121 & 1200 \\
\hline 1605 & 201201222 & 1200000 \\
\hline & 2101212 & 120000 \\
\hline & (3) & 1000 \\
\hline
\end{tabular}

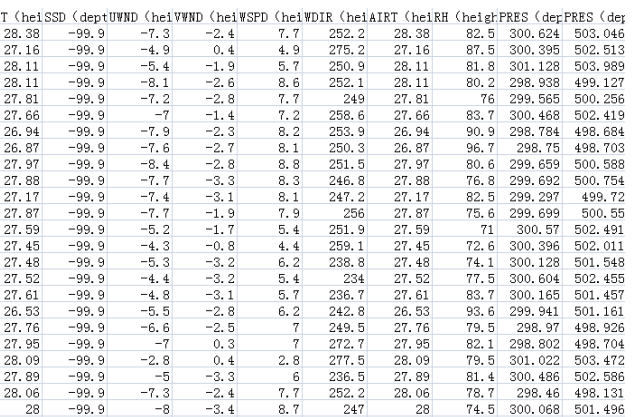

We can choose the data collected in a certain day (eg. 9 $\left.19^{\text {th }}, 2016\right)$ to do the factor analysis. We can also choose the mean values of data collected in a certain month or a year to do the data analysis. According to the variance contribution rates of the factors, the first five common factors' variance contribution rates reach $90.3 \%$.

Value of general factor $\mathrm{F}$ is the weighted value of $\mathrm{F}_{1}, \ldots, \mathrm{F}_{\mathrm{k}}$. We get the value of $\mathrm{F}(\mathrm{FF})$ in through the equation :

$$
F=9.889 F_{1}+\ldots+1.037 F_{5}
$$

Then we get the result in the chart below by calculating the value of $\mathrm{F}$ with formula FF.

Tab. 5. FF Values

\begin{tabular}{|c|c|c|}
\hline $\mathrm{fb}$ & F & $\mathrm{FF}$ \\
\hline T8N165E & 5.41 & \\
\hline T0N165E & 45.52 & 40.11 \\
\hline T8S165E & -0.73 & -46.25 \\
\hline T8N180W & 1.11 & 1.84 \\
\hline T0N180W & -0.67 & -1.78 \\
\hline T8S180W & -0.73 & -0.06 \\
\hline T8N170W & 0.37 & 1.1 \\
\hline T8S170W & -1.18 & -1.55 \\
\hline T8N155W & -0.61 & 0.57 \\
\hline T0N155W & -6.52 & -5.91 \\
\hline T8S155W & -3.93 & 2.59 \\
\hline T9N140W & 6.43 & 10.36 \\
\hline T5S140W & -3.83 & -10.26 \\
\hline T8N125W & 5.84 & 9.67 \\
\hline T0N125W & -8.57 & -14.41 \\
\hline T8S125W & -5.39 & 3.18 \\
\hline T8N110W & -4.8 & 0.59 \\
\hline T2S110W & -9.78 & -4.98 \\
\hline T8S110W & -6.66 & 3.12 \\
\hline T8N95W & -4.93 & 1.73 \\
\hline T0N95W & -6.37 & -1.44 \\
\hline
\end{tabular}


We made Fig. 4 by making the scatter graph of the value of $\mathrm{FF}\left(\mathrm{FF}_{\mathrm{i}}\right)$ we got at the beginning and the value of $\mathrm{FF}\left(\mathrm{FF}_{\mathrm{i}+1}\right)$ we got afterwards. The reason might be the small quantity of station data we analyzed or there were some other changes in the sea area that day. It needs more specific analysis and study by the local inspecting people to make it clearer.

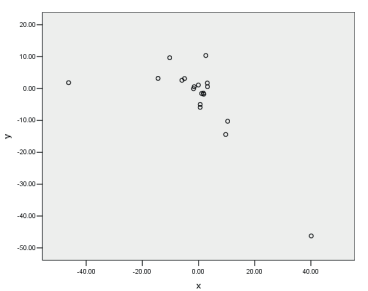

Fig.4. Scatter graph of the value of FF (FFi) got earlier and afterwards

We choose the data from a certain monitoring station (like T8N165E) to do cluster analysis according to the time line. The sampled time length is 1488 days from $1 / 1 / 2012$ to $4 / 8 / 2017$. After cluster analyzing, we found that the data should be sorted into three time periods. Then we applied $\mathrm{k}$-mean value clustering analysis method and got the data process result of each station. According to the analyzing result, we made the time-cluster analyzing line chart (Fig. 5) below.

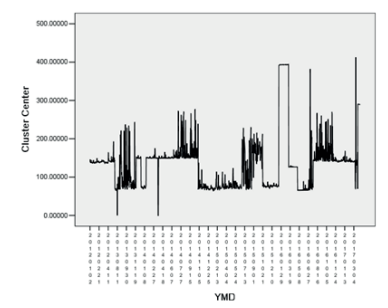

Fig.5. Time-cluster Analyzing line chart

We can see that the station has different conditions in different time periods. We need to pay more attention to the time spot appeared in the graph.

We can also sort the seawater quality into tree levels according to the seawater quality standard and the medium value of the cluster analyzing results thus to estimate the water quality in each time period. Level one suit for protecting the marine biological resources and the safety for human to use. Level two suit for bathing beaches and scenic spots. Lever three suit for developing industries, harbour water, and some other sea developing working area[14,15].

\section{RESULTS}

The visualization study of the marine data is of critical importance due to the huge quantity, it's varied attributes and multi-resolution of it[16]. Building the ocean model and the visualized model of marine data has become a very important research subject in studying the digital ocean.

\section{DISCUSSION}

We did some supplements to the original data when we realized there was so much missing information in the sampled data. This also reminds people to check if there are any malfunctions on the buoy, and if so, it calls for timely maintenance.

In this article, we did cluster analysis to the marine data due to its time attributes. We can do further analysis to the data with orderly cluster method to determine the rules since time has its continuity. After clustering, we can make prediction with discriminant analyzing method. Better effects could be achieved through combined effort of analyzing according to time and space factors which is in our future work. In this article we did the analysis separately.

\section{ACKNOWLEDGEMENTS}

This research is supported by National Natural Science Foundation of China under Grant No. 61375066.

\section{BIBLIOGRAPHY}

1. Smirnov G.V., Olenin A.L.: Marine information systems and new measuring channels for hydrophysical parameters, Oceanology, Vol.55, pp.291-295, 2015.

2. Andreas M., Gunther R. : Review of three-dimensional ecological modeling related to the North Sea shelf system. Part 1: models and their results, Progress in Oceanography, Vol.57, no.2, pp. 175-217,2015.

3. Helman J, Hesselink L.: Representation and Display of Vector Field Topology in Fluid Flow Data Sets, IEEE Computer, Vol.22, no.8, pp. 27-36,1989.

4. Leeuw W. D., Liere R. V.: Multi-level topology for flow visualization, Computers \& Graphics, Vol.24, no.3, pp.325-331,2000.

5. Reinders F., Post F.H., Spoelder H.J.W.: Visualization of time-dependent data with feature tracking and event detection,The Visual Computer, Vol.17, no.1, pp.55-71,2001.

6. Marsh J., Glencross M., Pettifer S., and Hubbold R.: A network architecture supporting consistent rich behaviour in collaborative interactive applications, IEEE Transactions on Visualization and Computer Graphics, Vol.12, no.3, pp.405-416,2006.

7. Evangelinos C., Lermusiaux P. F. J., Geiger S. K., et al.: Web-enabled configuration and control of legacy codes An application to ocean modeling, Ocean Modelling, Vol.13, no.3, pp.197-220, 2006. 
8. Dai H.L., Mou N., Wang C.Y., et al. : Development status and trend of ocean buoy in China, Meteorological Hydrological and Marine Instruments (in Chinese), Vol.2, 2014.

9. Zhang Feng, Li Sihai, Shi Suixiang: Research of Data Architecture in Digital Ocean, MarJne Science Bulletin, Vol.12, pp.85-96,2010.

10. Levitus S., Antonov J. I., Boyer T.P., et al.: World ocean heat content and thermosteric sea level change $(0-2000 \mathrm{~m})$ 1955-2010, Geophysical Research Letters, Vol.39, no.10, pp.L10603-L10607,2012.

11. Cummings J.: Operational multivariate ocean data assimilation, Quarterly Journal of the Royal Meteorological Society, Vol. 131, issue 613, pp.3583-3604, 2005.

12. Chau K., Muttil N.: Data mining and multivariate statistical analysis for ecological system in coastal waters. Journal of Hydroinformatics, Vol.9, no.4, pp.305-317,2007.

13. Chuang, S.S., Wu, K.T., Lin, C.Y. et al.: Poincaré plot analysis of autocorrelation function of $R R$ intervals in patients with acute myocardial infarction, J Clin Monit Comput, Vol.28, pp.387-401,2014.

14. Hatzikos E., Hätönen J., Bassiliades N., Vlahavas, I., Fournou, E.: Applying adaptive prediction to sea-water quality measurements, Expert Systems with Applications, Vol.36, pp.6773-6779,2009.

15. Shrestha S., Kazama F.: Assessment of surface water quality multivariate statistical techniques: a case study of the Fuji river basin, Japan Environmental Modelling and Software, Vol.22, pp. 464-475,2007.

16. M. J. Martin, M. Balmaseda, L. Bertino, et al.: Status and future of data assimilation in operational oceanography, J. Oper. Oceanogr. , Vol.8, no.S1, pp.28-48,2015.

\section{CONTACT WITH THE AUTHOR}

Li Yajie

e-mail:lyj7712@163.com

tel.: 86-10-62282322

Beijing University of Posts and Telecommunications Beijing, 100876

China 